\title{
A Multidisciplinary Approach to the Prevention and Treatment of Obesity
}

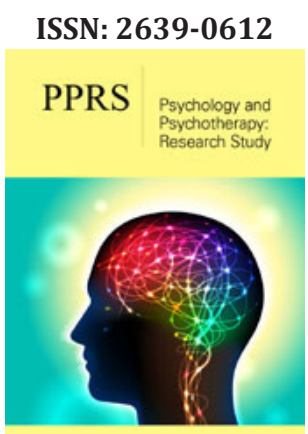

*Corresponding author: Pruneti C, Department of Medicine and Surgery, Clinical Psychology Labs, Italy

Submission: 皆 January 28, 2020 Published: 紫February 05, 2020

Volume 3 - Issue 3

How to cite this article: Pruneti $\mathrm{C}$, Buracchi G. A Multidisciplinary Approach to the Prevention and Treatment of Obesity. Psychol Psychother Res Stud. 3(3).PPRS.000563.2020.

DOI: 10.31031/PPRS.2020.03.000563

Copyright@ Pruneti C, This article is distributed under the terms of the Creative Commons Attribution 4.0 International License, which permits unrestricted use and redistribution provided that the original author and source are credited.

\author{
Pruneti C* and Buracchi G \\ Department of Medicine and Surgery, Clinical Psychology Labs, Italy
}

\begin{abstract}
The aim of this study is to examine the increasing phenomenon of obesity, not yet considered as an alimentary behaviour disease, but only as a somatic condition. The treatment of obesity is nowadays largely based on psychological approaches directed to produce modifications in lifestyle and not only in alimentary behaviour. Some strategies for prevention are discussed, considering that all the examined studies emphasize four factors as the determinants for the increase of overweight: excessive caloric supply, lack of physical activity, difficulty in recognizing consequences of ponder excess, difficulty in modifying consolidated behavioural habits. For this reason, a substantial change in the perception of the phenomenon, and of cultural and psycho educational politics are needed.
\end{abstract}

Keywords: Obesity; Lifestyle; Bulimia; Binge eating; Anorexia

\section{Introduction}

Even though the term "obesity" derives from the Latin term observe, which means eating too much, it cannot be included among the alimentary behaviour diseases and is not classified as such. Currently, obesity is often considered and described as a somatic condition. Well defined on a morphological basis, as an excess of fat mass but it is not associated to specific distorted profiles of personality, of behaviour, etc. On the contrary, in the general clinical practice, the treatment of obesity is also largely based on psychological and psychotherapeutic approaches directed to produce modifications in lifestyle and not only in alimentary behaviour, like improve physical activity and in other psychological areas. Presently obesity, commonly agreed as a somatic condition of excess of fat mass, can be considered as the "point of arrival" of the alimentary troubles classified in the DSM-5 [1]; (Figure 1). This is frequent in the cases of bulimia, and especially for the subtype without behaviours of elimination, the binge eating disorder. Obesity is also the result of $2 \%$ of the cases of anorexia, due to the metabolic imbalances that this disease can produce especially if not adequately treated with an interdisciplinary approach. Since not all cases of obesity are caused by such dynamics, a further close examination of these subjects seems useful.

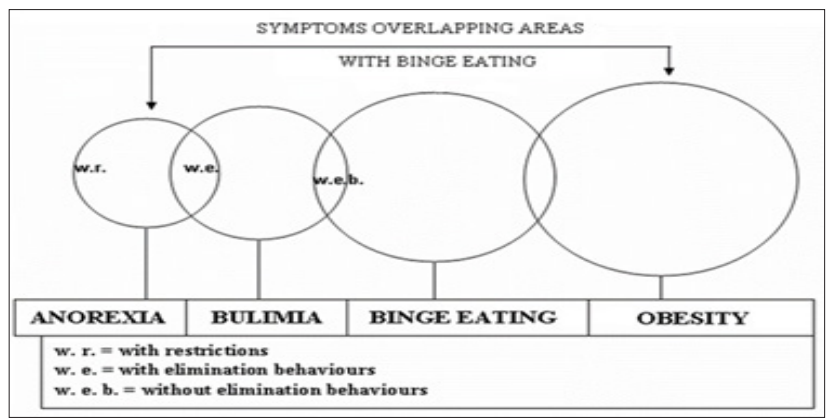

Figure 1: Heating disorders spectrum, symptoms overlapping areas.

\section{Classification}

According to the predominant interest, it is possible to classify obesity in relation to the following parameters: 
a. Number and dimension of adipocytes (we can distinguish a hyperplasic obesity, typically established during infancy and due to an elevated number of adipose cells and a hypertrophy obesity, proper of the adult due to an increase in volume of the adipocytes).

b. Body mass index (BMI) which is obtained dividing body weight (expressed in $\mathrm{Kg}$ ) by the square of the height (expressed in meters). Moderate obesity if BMI is between 30 and $35 \mathrm{Kg} / \mathrm{m}^{2}$, severe obesity if it is between 35 and $40 \mathrm{Kg} / \mathrm{m}^{2}$ and serious obesity if it is greater than $40 \mathrm{Kg} / \mathrm{m}^{2}$; distribution of adipose mass.

It is possible also distinguishes an android type obesity, in which there is a greater concentration of adipose mass in the abdominal zone and a female type obesity, in which the fat is mostly located on thighs, gluteus and hips. Since the adipose mass in the visceral area (android type obesity) constitutes a risk factor for metabolic and cardiovascular diseases, it is profitable to estimate the accumulation of fat in this zone. One of the most valid indicators of visceral distribution is the WHR (Waist-Hip Ratio), which results from the relationship between circumference of the abdomen and of the hips; clinical metabolic complications can emerge for values $>1$ in men, and for values $>0,9$ in women.

\section{Etiology}

Under the term obesity, it is possible to find many conditions that we could define "obesities", underlining the great etiological variability. Obesity can technically be defined as a BMI $>30$, a numerical value that corresponds approximately to an increase of body weight equal to $20 \%$ over the ideal weight, without considering, however, neither the type of adipose accumulation nor the fat distribution in different body districts. Studies on offspring of obese parents and on twins (both mono and decrials) show that genetic factors are clearly predominant in the genesis of obesity, so much that it seems that they are responsible of up to $70 \%$ of the BMI variability. Results from studies carried out on adopted children [2,3] show correlations between children's BMI their biological parents and not with their adoptive parents. Is obesity a phenomenon that is fundamentally due to genetic inheritance and therefore scarcely modifiable?

Inheritance as a principal cause of the great increase of this phenomenon reported in the United States and in Europe and in other western countries, whose trends of obesity resemble in greater or smaller measure those of the United States. Probably there are genotypes that are more sensitive than others are to environmental changes (alimentary facts, physical activity, stress response, etc.). Since the 90's years of the last century, Bouchard and co-workers studies on the positive energetic budget, subsequent to excessive alimentation, extended for 100 days on 12 pairs of healthy monozygotic, normal weight and sedentary twins, without a family history of obesity or other metabolic illnesses [4]. This study underlined the low variability in the response to the excessive alimentation inside the couple, while it was higher among the various couples. They found an average increase among the couples of $8.1 \mathrm{Kg}$ of weight, (range-4.3-1.33Kg). Moreover, if the genome is similar, the answer will be similar, but when facing an extended period of hyper alimentation, all the genomes tend to produce an increase in weight or in body fat even if in diversified ways. A model that allows to better understand the deep causes of what is happening in rich countries, comes from the studies of Neel [5] concerning the Pima Indians, a native population of Arizona, devoted to an agriculture of subsistence along the shores of the Gila river. In the drought years, the agricultural production decreased, and the Pima had periods of famine, but in the favourable years, they lived periods of comfort, which allowed the population to accumulate a minimum adipose panicle, which decreased in periods of famine. However, they lived in equilibrium with their own resources. In the middle of the $19^{\text {th }}$ century, white people, diverting the course of the river, provoked the destruction of most of the Pima population. Subsequently the Pima survived moved to reserves where they conducted a sedentary life, subsidized by government funds, and started to eat fats and sugars. In a few years, they developed almost epidemically obesity, type II diabetes and hypertension. The hypothesis of Neel was that the sudden appearance of these problems, before unknown among the Pima, was nothing other than the consequence of the expression of a "saving gene" (thrifty genotype), that had allowed the Pima to live in harmony with the resources of their native territory. It is not surprising, therefore, that today the prevalence of these illnesses is clearly lower among the Pima who live in Mexico, in comparison to those who live in Arizona, since the first ones were able to maintain a traditional life style, with more physical activity and a diet that includes less fats and more complex carbohydrates.

Along with individual differences in the genotype, primary obesity should always be considered dependent from an imbalance between caloric income and energetic consumption. Also, even if the velocity of forming surplus fat mass, as well as the entity of this fat mass, and the greater or lower difficulty in losing this excess, when adhering to a hypo caloric diet, is strongly conditioned by the genome. A particular aspect concerns the destiny of obese children, in which the risk of becoming obese adults varies between two and 6.5 times in comparison with non-obese children. The relative risk for an obese child to become an obese adult increases proportionally with age; in fact, almost $40 \%$ of obese children will become obese adults and this percentage climbs to $70 \%$ for obese teen-agers.

\section{Strategies of prevention}

Following these considerations, the importance of strategies of prevention of the phenomenon of overweight/obesity is clear. The approach to prevention should start in infancy or childhood and last in the whole life course, as normally recommended by the OMS for all non-transmissible illnesses [6]. It is therefore fundamental to understand which the determinants of the increase of overweight are in infancy and in adolescence. Almost the totality of the examined studies emphasizes four factors: excessive caloric supply; lack of suitable physical activity; difficulty in recognizing consequences of ponder excess or, however, of an unbalanced feeding on health, and difficulty in modifying behavioural habits 
(Figure 2). The first problem that some politics of prevention have to face, concerns the relative rarity of longitudinal studies, with repeated measures, in which the changes in diet and physical activity are connected to changes of weight [6]. This is why some studies such as "The Planet Health Obesity Prevention Program" [7] appear of particular interest. This study involved 480 adolescent girls (between 10 and 14 years old) for two years, appraising how a scholastic prevention program can be effective in preventing obesity, using healthy feeding and physical activity, and can also produce a reduction of over $50 \%$, in the use of self-induced vomit and laxatives use for weight self-control. In the USA, the Georgia's FITKID Project has shown the intervened difference, during a threeyear period, due to the exposure of boys of primary schools to a "phytogenic" environment, in comparison with controls statements to an "obesogenic" environment [8]. The intervention consisted in both healthier diet and increase of physical activity. Compared with the controls, the subjects exposed to a "phytogenic" environment showed meaningful differences with benefits in their health. Unfortunately, as it emerges from an Australian study carried out on boys of 7-8 years and 10-11 years [9] as well as on their parents, while the awareness of the importance of a healthy diet is elevated, the same cannot be said on the perception of the importance of physical activity [10]. The causes of the lack of physical activity in infancy and adolescence are certain manifold, even if various studies focus their attention on the role of sedentary activity as watching TV and the use of videogames. As regards to videogames a Swiss study shows how the use of videogames by boys in the first three years of primary school, is positively associated with both overweight and obesity, independently from other factors such as the use of television [11].

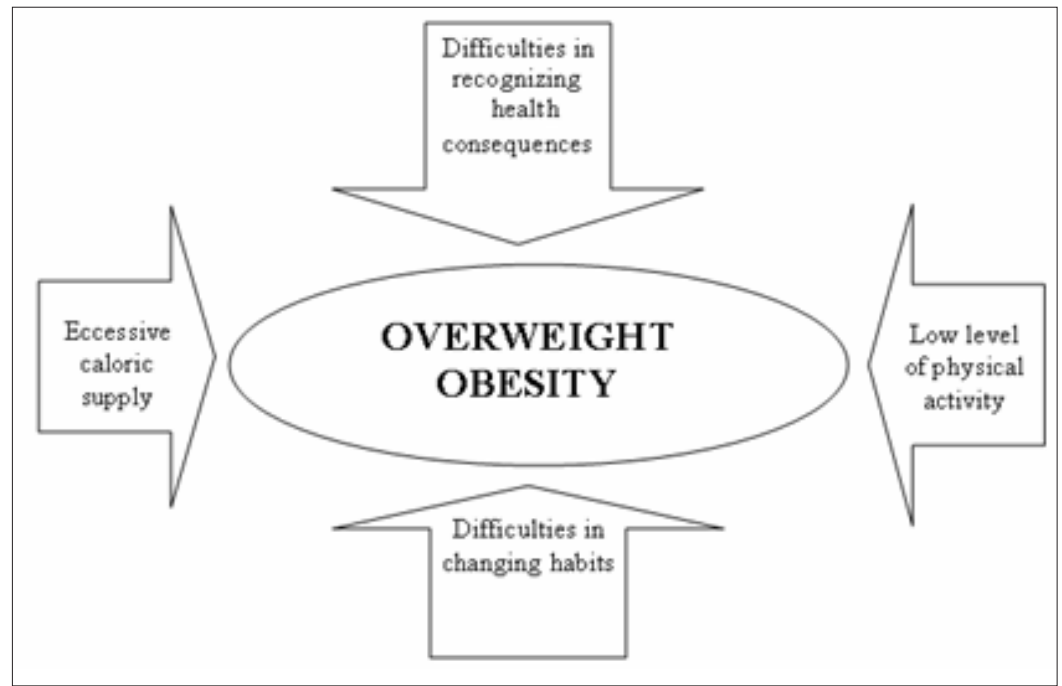

Figure 2: The four factors involved in obesity.

Regarding the use of television there is a positive correlation between the numbers of hours spent watching TV, overweight and obesity compared to the general population. The increase of the prevalence of obesity in infancy has also been proven proportional to the increase in the number of hours devoted to children by the TV networks. The influence of TV is then double, since it not only induces a reduction of physical activity, but it also induces, through contemplated spots, the consumption of a great number of alimentary products, defined today as junk-food, with high caloric content and low nourishing value [12]. However, there are factors that contribute to the general reduction of physical activity, which is tightly connected to the genesis of obesity, as underlined in the program entitled: "Colorado on the Move (COM)" which distributed an electronic pedometer to 1098 adult subjects. Thanks to a research it has been underlined that obese subjects $(\mathrm{BMI} \geq 30)$ showed less than 2000 footsteps/die, compared to a general average of 6804 of the sample, average, however, clearly inferior to the 10000 or more recommended $[13,14]$.

\section{Conclusion}

Obesity is considered as a global epidemic in industrialized countries, even if many signs help us understand that this phenomenon also concerns developing countries, even in areas of the world where the problem of malnutrition still exists, with $\mathrm{BMI} \leq 18.5$. Causes of this phenomenon are manifold and in general might be sought in the social changes of the XX century, such as the processes of urbanization and modernization, as broadly described by the American Obesity Association [13]. The most worrisome phenomenon is the increase of overweight and obesity in infancy and in adolescence, that will have, as a result, a further increase in the incidence of this phenomenon among adults. Unfortunately, even though obesity is now one of the first causes of death, and in some countries such as the United States even the first cause of death, this phenomenon is today still considered as an individual problem. This situation requires a substantial change in the perception of the phenomenon and cultural and educational politics that act on the principle responsible factors, such as the lack of physical activity 
and the excessive caloric supply, increasing the awareness of this phenomenon in the public opinion, beginning from the educational and scholastic structures.

\section{References}

1. American Psychiatric Association (2013) Diagnostic and statistical manual of mental disorders. ( $5^{\text {th }}$ edn), APA, Washington DC, USA.

2. Stunkard AJ, Sorensen TIA, Hanis C, Teasdale TW, Chakraborty R, et al. (1986) An adoption study of human obesity. N Engl J Med 314(14): 193198.

3. Price RA, Cadoret RJ, Stunkard AJ, Troughton (1987) Genetic contributions to human fatness: An adoption study. Am J Psychiatry 144(8): 1003-1008.

4. Bouchard C (1990) Individual differences in the response to regular exercise. Int J Obes 4: S558.

5. Neel JV (1962) Diabetes mellitus: A thrifty genotype rendered detrimental by progress. Am J Hum Genet 14: 353-362.

6. Seidell JC, Nooyens AJ, Visscher TL (2005) Cost-effective measures to prevent obesity: Epidemiological basis and appropriate target groups. Proc Nutr Soc 64(1): 1-5.

7. Austìn SB, Field AE, Wiecha J, Peterson KE, Gortmaker SL (2005) The impact of a school-based obesity prevention trial on disordered weight- control behaviours in early adolescent girls. Arch Pediatr Adolesc Med 159(3): 225-230

8. Yin Z, Hanes J, Moore JB, Humbles P, Barbeau P, et al. (2005) An afterschool physical activity program for obesity prevention in children: The medical college of Georgia fit kid project. Eval Health Prof 28(1): 67-89.

9. Hesketh K, Waters E, Green J, Salmon L, Williams J (2005) Healthy eating, activity and obesity prevention: A qualitative study of parent and child perceptions in Australia. Health Promot Int 20(1): 19-26.

10. Stettler N, Signer TM, Suter PM (2004) Electronic games and environmental factors associated with childhood obesity in Switzerland. Obes Res 12(6): 896-903.

11. Caroli M, Argentieri L, Cardone M, Masi A (2004) Role of television in childhood obesity prevention. Int J Obes Relat Metab Disord 28 Suppl 3: S104-S108.

12. Wyatt HR, Peters JC, Reed GW, Barry M, Hill JO (2005) A Colorado statewide survey of walking and its relation to excessive weight. Med Sci Sports Exerc 37(5): 724-730.

13. (2005) AOA Facts Sheets.

14. Innocenti A, Franzoni F, Pruneti C (2014) The role of nutrients in a dietary intervention in improving blood cholesterol profile and lowering cardiovascular risk. Journal of Basic \& Applied Sciences 10: 96-101. 